\title{
Radiocarbon
}

1980

\section{ARCHAEOLOGY AND RADIOCARBON DATING}

\author{
WILLARD FRANK LIBBY ${ }^{\dagger}$ \\ University of California at Los Angeles
}

Paper delivered at the one hundredth anniversary meeting of the

Archaeological Institute of America, December, 1979

Boston, Massachusetts

INTRODUCTION

Tonight I have the opportunity to thank my many archaeological collaborators in the early days of radiocarbon dating. The development would not have been possible without their wonderful cooperation. We began, Dr James Arnold and I, with the help of Dr Ernest C Anderson, with the bright hope that we could obtain priceless samples of early dynastic Egypt for checking merely by the asking. Dr Arnold's father was an amateur archaeologist, and he gave us some early hints. Through him we obtained some valuable material from the Metropolitan Museum.

Our very first date was Acacia wood from the tomb of Zoser at Sakkara through the kindness of Ambrose Lansing of the Metropolitan Museum. Dr John Wilson of the Oriental Institute of the University of Chicago, where this research was done, estimated the age to be 4650 , whereas we obtained 3979 . Correcting for the half-life, 3 percent, we obtain 4100 years, relative to the time of 1950 (вР). So, we see that in the very first sample, had we taken it more seriously, our date was younger than the historical date. This later turned out to be an important matter, for we find that all dates in that span of time must be corrected for an increased cosmic ray intensity presumably due to a weakening of the earth's magnetic field. Mr Arnold put us on to Mr Lansing, and we obtained some material. But we also learned rather quickly that this was not going to be an easy process. We must, in any case, have someone to introduce us. We asked for help from the Archaeological Institute and the American Geological Society who kindly appointed us a most helpful Committee: Frederick Johnson, Chairman, Don Collier, Richard Foster Flint, and Froelich Rainey. Fred, as you know, is an archaeologist along with Froelich Rainey and Don Collier. Dick Flint was a geologist. We rapidly came to the policy of asking this Committee to advise us and to help us procure pertinent samples.

THE COLLABORATION

After the first sample was measured (C-1), Froelich Rainey obtained a Cyprus beam from the tomb of Sneferu at Maydum (C-12), and Don

+ Deceased September 1980 
Collier got us wood from the deck of the funerary ship from the tomb of Sesostris III. This was an interesting episode, for the Committee had not been appointed. We had to deal with the Director, and there was no room for doubt about his position. Namely, he did not see why we should be given a part of the ship to burn. But Don Collier, who was on the staff of the Natural History Museum where the funerary ship was on exhibit, managed for us. From then on, through the good auspices of the Committee, we were blessed with a series of some 800 samples. By the way, I speak tonight only of the work which was done at the University of Chicago by Arnold, Anderson, and myself.

In the following years many other laboratories joined and many tens of thousands of dates now are available. But these dates were measured by us in our Chicago laboratory working with our archaeologist collaborators. That was 30 years ago.

The next sample beyond Sesostris (C-12) on our Chicago Date List is called Ptolemy (C-62). It consisted of wood from a coffin from the Egyptian Ptolemaic Period dated by John Wilson of the Oriental Institute at about 2280 years. We obtained agreement within our rather substantial error which in those days was running about 2 or 3 centuries. This sample was given us by John Wilson and his colleague, Watson Boyes, of the Oriental Institute.

The next sample on our list called Hemaka was submitted by $\mathrm{W} \mathbf{B}$ Emery of the British Embassy in Cairo through the auspices of our friends in the Oriental Institute. It consists of a slab of wood from the roof beam of the tomb of the Vizier Hemaka who was contemporaneous with the First Dynasty of Sakkara with an expected age according to $\mathrm{R} J$ Breakwood of the Oriental Institute of between 4700 and 5100 years. Our average was $4883 \pm 200$.

Our next sample was middle pre-Dynastic charcoal from El Omari near Cairo, Egypt. This was dated at $5256 \pm 230$ years, in general agreement with expectations. This material was furnished by Ferand de Bono of the Service of Antiquities of Egypt in Cairo.

The next sample was very exciting - wheat and barley grain from the Upper $\mathrm{K}$ level of the Fayum A material submitted by Gertrude Cayton-Thompson and Mrs Elise Baumgartel of the University of Manchester. The date was 6300 years.

Well, you see how after only half a dozen dates we were being blessed by contributions from world distinguished archaeologists. I think that I must turn now to the beginning and fill in some of the gaps.

We had a period of 2 or 3 years of secret research when we believed that the notion of radiocarbon dating was beyond reasonable credence, and therefore, we would not disclose our plans and purposes until we had results. This meant that the funding of our research rested entirely on the University of Chicago and my own meager resources. Fortunately, these were adequate. We chose to break the problem into parts, each part being of interest to some other group who would help finance it. For example, our measurement of the half-life of radiocarbon was financed by 
the Argonne National Laboratory and, of course, ultimately, by the Atomic Energy Commission.

However, the costs of the counters and electronic equipment and the first crude anticoincidence shield were entirely borne by a $\$ 2500$ grant by the University through Dean Walter Bartky. I arrived at the University of Chicago in October, 1945, having been appointed Professor in the Institute of Nuclear Studies and the Department of Chemistry. But I had a number of researches in mind. After four years of intensive work on war-time problems, we had a tendency to lean towards problems of no particular application and to try to get away from the intensive concentration characteristic of military research. Sam Allison, our Institute director at that time, said he was going to study the color of butterfly wings. Well, I never said anything of that sort, but we were, however, considering the idea of how to use the cosmic rays to measure human history and time for geological events. The principles are well known to you, but they are: the bombardment of the high atmosphere by cosmic rays produces radiocarbon, mass, 14, half-life 5730 years. This oxidizes and enters the biosphere and renders things radioactive at a constant level because of the long time allowed for mixing. So we predicted from the intensity of cosmic rays measured by our colleague and friend, Serge Korff of New York University, the rate at which ${ }^{14} \mathrm{C}$ atoms were being produced, and assuming that the rate had been true for all of the preceding 50,000 years, we calculated what the general level of ${ }^{14} \mathrm{C}$ should be in living matter. It was the confirmation of this calculation by measurement of the ${ }^{14} \mathrm{C}$ of methane gas derived from Baltimore sewage that gave us the courage to move forward to radiocarbon dating. So at the time that we obtained our very first confirmation, through our friend, Harold Urey, Dr Paul Fejos of the Viking Fund (now the Axel Wenner-Gren Foundation) learned of our work. We had given a seminar at the University of Chicago explaining and giving evidence that we could actually do dates by using it. At that time, Dr Fejos came to the University of Chicago to look into our researches and presented us with a substantial check from the Viking Fund. From this time onward we had enough money to do our dating and we were able to build a new anticoincidence shield and to generally upgrade our equipment. We received several hundred samples.

Though it is very difficult in a few minutes to give proper credit to the dozens and dozens of archaeologists who helped us by giving us samples and advising us in our work, I would like to say that it has been the happiest experience of my long life-time to see how people so different in backgrounds as archaeologists and physical chemists could collaborate on fundamentally interdisciplinary research. They did learn the principles of radiocarbon dating, and we learned something about the field methods of archaeologists. Between us we worked out some guide rules as to how to select and preserve them for dating. 
Some results were outstanding. First, although the dates we found were younger, within experimental error, we confirmed the dates of the early dynasties in Egypt. We also showed that the heartwood of the redwood tree with 3000 rings that could be counted directly, showed the proper radiocarbon concentration. We showed that the abundant material from the Greco-Roman Period checked beautifully. However, as time went on and our measurement technique became more accurate, it became clear that our dates at about 5000 years were falling short of the mark by a deviation of about 500 to 800 years. We were able to calibrate this deviation due to the fortunate circumstance that there is rapid worldwide mixing of any ${ }^{14} \mathrm{C}$ introduced into the atmosphere. This knowledge is largely due to Hans Suess at La Jolla, Paul Damon of Arizona, and Elizabeth Ralph of the University of Pennsylvania Museum. The dating of wood from the Bristlecone Pine forest in the Schulman Grove in the White Mountains of the Sierra Nevada in California allowed us to go back to the early dynasties of Egypt and to make an absolute measurement. This curve of correction is now used and applies back to 8000 years. With this in hand, it is possible to recalculate the earlier measurements, and, in fact, to re-measure many of the samples. Through the kindness of Dr Edwards of the British Museum we were able to obtain a second set of samples from the early dynasties of Egypt to remeasure with modern techniques. The use of the Bristlecone Pine correction showed that the agreement with the historical values was excellent.

Thus, it seems that, at the moment, we have a method of worldwide, absolute dating back to 8000 years.

If we go further back in time we have no choice but to record our dates as radiocarbon dates and hope for a future development of other methods of dating which can be used to calibrate. It is just conceivable that an adequate understanding of the earth's magnetic field will help us. Thus, we see that geophysics enters into the problem. It is largely accepted that the general increase in cosmic ray intensity 5000 years ago was due to a weakening of the earth's magnetic field which, at the present time, deflects about half the primary cosmic rays that otherwise would hit the earth.

I want to thank the Archaeological Institute of America for inviting me tonight, but more particularly to thank all of you for the collaboration and help you have given to radiocarbon dating. 